Meta

Journal des traducteurs

Translators' Journal

\title{
Translating with an Injured Brain: Neurolinguistic Aspects of Translation as Revealed by Bilinguals with Cerebral Lesions
}

\section{Adolfo M. García}

Volume 60, numéro 1, avril 2015

URI : https://id.erudit.org/iderudit/1032402ar

DOI : https://doi.org/10.7202/1032402ar

Aller au sommaire du numéro

\section{Éditeur(s)}

Les Presses de l’Université de Montréal

\section{ISSN}

0026-0452 (imprimé)

1492-1421 (numérique)

Découvrir la revue

Citer cet article

García, A. M. (2015). Translating with an Injured Brain: Neurolinguistic Aspects of Translation as Revealed by Bilinguals with Cerebral Lesions. Meta, 60(1), 112-134. https://doi.org/10.7202/1032402ar
Résumé de l'article

Malgré les progrès dans l'étude psycholinguistique de la traduction, l'exploration de ses bases cérébrales s'avère limitée et dispersée. La traductologie a commencé à s'intéresser aux données neuroscientifiques pertinentes en se focalisant sur des études d'imagerie cérébrale. Pour aborder la question, cet article considère une source de renseignements également importante : les données cliniques. En particulier, la présente revue offre une interprétation de 21 cas de patients cérébrolésés bilingues avec troubles de la traduction. Trois hypothèses neurofonctionnelles et trois hypothèses neuroanatomiques sont proposées à partir du modèle hiérarchique et du modèle déclaratif/procédural, respectivement. En faveur des prédictions pertinentes, les données suggèrent qu'il y a des voies neurofonctionnelles indépendantes pour la traduction et la production verbale unilingue; pour la traduction directe et la traduction inversée ; et pour la traduction au niveau formel et au niveau conceptuel. De plus, les données indiquent que la traduction de mots et de phrases dépendent de régions cérébrales postérieures impliquées dans la mémoire déclarative, et de régions frontobasales impliquées dans la mémoire procédurale, respectivement. Aussi, les voies de traduction semblent être localisées exclusivement dans l'hémisphère gauche. 


\title{
Translating with an Injured Brain: Neurolinguistic Aspects of Translation as Revealed by Bilinguals with Cerebral Lesions
}

\author{
ADOLFO M. GARCíA \\ National Scientific and Technical Research Council, Institute of Cognitive Neurology \\ (Laboratory of Experimental Psychology and Neuroscience), Buenos Aires, Argentina \\ Faculty of Elementary and Special Education, National University of Cuyo, Mendoza, \\ Argentina \\ UDP-INECO Foundation Core on Neuroscience (Diego Portales University), Santiago, Chile \\ adolfomartingarcia@gmail.com
}

\section{RÉSUMÉ}

Malgré les progrès dans l'étude psycholinguistique de la traduction, l'exploration de ses bases cérébrales s'avère limitée et dispersée. La traductologie a commencé à s'intéresser aux données neuroscientifiques pertinentes en se focalisant sur des études d'imagerie cérébrale. Pour aborder la question, cet article considère une source de renseignements également importante: les données cliniques. En particulier, la présente revue offre une interprétation de 21 cas de patients cérébrolésés bilingues avec troubles de la traduction. Trois hypothèses neurofonctionnelles et trois hypothèses neuroanatomiques sont proposées à partir du modèle hiérarchique et du modèle déclaratif/procédural, respectivement. En faveur des prédictions pertinentes, les données suggèrent qu'il y a des voies neurofonctionnelles indépendantes pour la traduction et la production verbale unilingue; pour la traduction directe et la traduction inversée; et pour la traduction au niveau formel et au niveau conceptuel. De plus, les données indiquent que la traduction de mots et de phrases dépendent de régions cérébrales postérieures impliquées dans la mémoire déclarative, et de régions frontobasales impliquées dans la mémoire procédurale, respectivement. Aussi, les voies de traduction semblent être localisées exclusivement dans l'hémisphère gauche.

\section{ABSTRACT}

Despite significant progress in the psycholinguistic study of translation, research on its neurological underpinnings has been limited and sparse. Translation scholars have recently taken an interest in relevant neuroscientific evidence, focusing on imaging studies. This paper addresses the issue by considering an equally important body of data: clinical evidence. Specifically, a hypothesis-driven analysis is offered of 21 cases of brain-lesioned bilinguals exhibiting translation disorders. Three neurofunctional and three neuroanatomical hypotheses are derived from the Revised Hierarchical Model and the Declarative/ Procedural Model, respectively. Consistent with relevant predictions, the evidence suggests that there are neurofunctionally independent routes for translation, as opposed to monolingual speech production; backward, as opposed to forward, translation; and formbased, as opposed to conceptually mediated, translation. Available data further indicates that word and sentence translation are critically subserved by posterior brain areas implicated in declarative memory, and by frontobasal areas implicated in procedural memory, respectively. In addition, translation routes appear to be entirely left-lateralized.

\section{MOTS-CLÉS/KEYWORDS}

procès cérébraux, aphasie bilingue, routes de traduction, modèle hiérarchique, modèle déclaratif/procédural

brain processes, bilingual aphasia, translation routes, Revised Hierarchical Model, Declarative/Procedural Model 


\section{Introduction}

Translation processes have been studied from several perspectives, such as linguistics, psycholinguistics, and cognitive psychology (Hurtado Albir 2001; Pöchhacker 2004). However, the study of the neural basis of translation has received comparatively little attention, and remains as "one of the chief known unknowns in translation studies" (Tymoczko 2012: 83). For example, in the last 20 years, the single-word translation paradigm was used in at least 25 behavioral psycholinguistic studies (for reviews, see French and Jacquet 2004; Kroll, van Hell et al. 2010), whereas only three studies have offered neuroanatomical or neurophysiological evidence on such a task (Klein, Milner et al. 1995; Price, Green et al. 1999; Janyan, Popivanov et al. 2009).

Despite the paucity of direct neurological evidence, translation scholars have recently developed brain-based views of translation processes (Moser-Mercer 2010; Diamond and Shreve 2010; Tymoczko 2012; García 2013). These approaches have focused on neuroimaging evidence. For instance, studies using high-spatial-resolution techniques (e.g., fMRI, PET) suggest that translation processes, irrespective of the translation unit, (i) predominantly engage the left hemisphere (LH) (Klein, Milner et al. 1995; Price, Green et al. 1999; Lehtonen, Laine et al. 2005; Hervais-Adelman, Moser-Mercer et al. 2011), (ii) always generate distinct activity in Broca's area (García 2013), and (iii) elicit wider activation patterns for forward than backward translation (Klein, Milner et al. 1995; Rinne, Tommola et al. 2000; Quaresima, Ferrari et al. 2002; see also Price, Green et al. 1999).

However, neurocognitive perspectives on translation have largely neglected an equally important body of data: clinical evidence - in particular, reports of translation disorders in brain-lesioned bilinguals. Clinical evidence has inspired influential theories in cognitive neuroscience, including models of language (Ullman 2001; Paradis 2004), memory (Squire 2008), and conceptual knowledge (Capitani, Laiacona et al. 2003). Specifically, the study of cerebral patients allows for the establishment of double dissociations, i.e., empirical observations in which damage to area A impairs function $\mathrm{X}$ but not $\mathrm{Y}$, whereas damage to area $\mathrm{B}$ compromises function $\mathrm{Y}$ but not $\mathrm{X}$. Such patterns suggest that functions $\mathrm{X}$ and $\mathrm{Y}$ are subserved by independent neural substrates, and that they are differentially related to areas A and B (Damasio 1994).

Research on bilinguals suffering from aphasia or other pathologies, such as Alzheimer's disease, has shown that native and non-native languages (L1s and L2s, respectively) are subserved by independent neural networks, although these may be located in a shared macroanatomical region (Paradis 2004). This finding is consistent with electrostimulation (Ojemann and Whitaker 1978; Rapport, Tan et al. 1983) and neuroimaging (Chee, Soon et al. 2003; Klein, Zatorre et al. 2006) evidence. Recovery from bilingual aphasia may follow eight different patterns (Paradis 1989). Both languages are recovered in parallel and to the same extent in roughly $76 \%$ of the cases (Paradis 2004). In the remaining cases, each language recovers at its own pace and/ or to a different degree. Which type of recovery occurs in each patient, and which language is better restored, depends on multiple factors, including age, premorbid IQ, education level, etiology, and lesion site (Paradis 1989; Green 2005). Also, some bilingual patients exhibit language-control deficits, such as pathological switching (Fabbro, Skrap et al. 2000). Neuroimaging evidence with healthy participants (Braver, 
Barch et al. 2001; Hernandez 2009) indicates that language switching is mainly subserved by the dorsolateral prefrontal cortex, an area not typically associated with language processing which proves crucial to maintain goal-related information and bias response selection. This suggests that language choice is a pragmatic rather than a strictly linguistic phenomenon (Fabbro 2001; Hernandez 2009).

Despite the ever-growing literature on bilingual aphasia, evidence on translation phenomena subsequent to brain damage has been produced sparsely. Case reports of bilingual patients rarely include assessments of translation skills, and those which do usually have only a few trials on relevant tasks. In this regard, Part $\mathrm{C}$ of the Bilingual Aphasia Test (BAT) (Paradis 1979), arguably the most comprehensive instrument for assessing translation abilities in bilingual aphasics, includes only 32 translation trials (20 words and 12 sentences, half in each translation direction).

These limitations notwithstanding, current understanding of the neurocognitive basis of translation could be fostered through a comprehensive, hypothesis-driven review of reports of neurological bilingual patients. To date, such a review seems to be lacking in the literature. Although previous studies have offered anecdotal illustrations of, and brief comments on, different translation neuropathologies, they have overlooked available (though scant) quantitative data and failed to provide integrative neurofunctional or neuroanatomical interpretations of the evidence (e.g., Fabbro 1999; 2001; Ijalba, Obler et al. 2004). Likewise, specific hypotheses on the organization of translation-specific routes have not been hitherto tested through a systematic, large-scale analysis of translation disorders subsequent to brain damage. The goal of this paper is to cover such a gap in the literature.

Most of the evidence considered herein comes from patients without formal translation training. Yet, the neural pathways supporting translation exist in all bilingual brains, as shown by the fact that even lay bilinguals can translate between languages (Malakoff 1992), albeit with varying results. Thus, the broad neurofunctional and neuroanatomical organization of translation-related (and possibly translation-specific) routes can be explored by studying either professional translators or bilinguals without formal translation training (see Section 5.2).

The remainder of the article is organized as follows. Section 2 consists in the postulation of six hypotheses on the neural organization of translation routes. Section 3 offers an integrative analysis of 21 cases of the four translation neuropathologies documented to date. The evidence is discussed in Section 4, and its implications for understanding professional translation within Translation Studies are addressed in Section 5. A final section acknowledges this study's limitations and suggests directions for future research.

\section{Hypotheses on the neural organization of translation routes}

The present hypotheses on the neural organization of translation routes come from two mainstream models in the study of bilingualism. Three neurofunctional hypotheses are taken from the Revised Hierarchical Model (RHM) (Kroll and Stewart 1994), and three neuroanatomical hypotheses are derived from the Declarative/Procedural Model (DPM) (Paradis 2009; Ullman 2001). These models have been chosen because of their prominence in the literature and their sound empirical foundation. 
The RHM has long dominated psycholinguistic research on word translation. In a fifteen-year period, the paper where it was first proposed accumulated over 300 citations in articles indexed by the Web of Science (Kroll, van Hell et al. 2010). This model solidly characterizes the functional organization of the routes supporting linguistic production processes, including translation.

For its own part, since its first formulation (Paradis 1994a), the DPM has been supported by an impressive body of evidence obtained in multiple clinical reports of aphasia, congenital language disorders, and neurodegenerative disease, as well as varied experimental studies using behavioral, electrophysiological, and neuroimaging techniques (Ullman 2001; Paradis 2004/2009). To date, it remains as a plausible and elegant account of the gross anatomical distribution of linguistic subsystems in the bilingual brain, which renders it a reasonable starting point to advance hypotheses on the neuroanatomical organization of translation routes.

The six hypotheses are next presented separately (see Table 1 in Appendix for a summary).

\subsection{Neurofunctional hypotheses}

The RHM (Figure 1) accounts for translation asymmetries in the bilingual lexicosemantic system.

FIGURE 1

The Revised Hierarchical Model (Kroll and Stewart 1994). Solid lines: stronger connections. Dashed lines: weaker connections

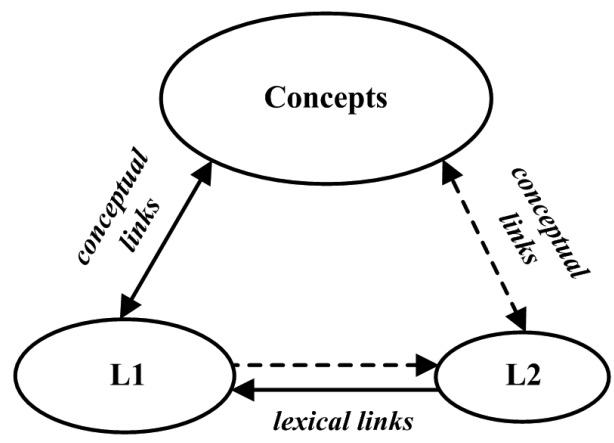

The model postulates three separate systems intervening in translation: a shared conceptual store, a store for L1 lexical representations, and a store for L2 lexical representations. Also, the RHM makes three key assumptions about the organization of translation routes, which give rise to distinct neurocognitive predictions.

First, the model assumes that the routes allowing for translation at the lexical level are separate from those involved in L1 or L2 production. ${ }^{1}$ Thus, this hypothesis predicts the existence of neurological lesions which result in impaired lexical translation skills with preserved spontaneous production skills in either language, and vice versa.

Second, the model postulates that there are functionally independent routes for backward translation (BT) and forward translation (FT). ${ }^{2}$ If this is correct, there 
should be patients in which either BT or FT are exclusively (or more significantly) impaired relative to the opposite direction.

Third, the model proposes that translation can be achieved through (i) a lexical route, consisting of direct connections between L1 and L2 word forms in the absence of conceptual activations, or (ii) a conceptual route, involving semantic mediation between languages. ${ }^{3}$ While the involvement of the conceptual system in most translation acts is unchallenged in the literature, the existence of a direct lexical route would be supported by cases of brain-lesioned bilinguals in which translation can be performed although the neurological insult impedes conceptual activations during the task.

\subsection{Neuroanatomical hypotheses}

The DPM characterizes the neuroanatomical organization of a bilingual's language systems. Three aspects are of particular interest to the present study. First, the model postulates that processing of word forms and associated semantic representations in both L1 and L2 is subserved by posterior brain structures implicated in declarative memory. Critical areas for these functions are the medial temporal lobe and the hippocampal gyrus, as well as regions of the temporal and parietal lobes.

Second, the DPM posits that L1 grammatical processing depends on frontobasal structures implicated in procedural memory, including the caudate nucleus and the putamen, as well as aspects of Broca's area. Instead, L2 grammar is subserved by different brain areas depending on the subject's age of L2 acquisition and/or level of L2 proficiency. If L2 grammar is learned metalinguistically, through formal instruction, after age seven, and it is subject to conscious control processes during verbal communication (e.g., late, unbalanced bilinguals), then it is subserved by the same gross neuroanatomical regions subserving word processing. On the other hand, if L2 grammar is incidentally acquired before age seven, and it is used automatically (e.g., early, balanced bilinguals), then it is represented and processed in the same areas subserving L1 grammar.

Third, and contrary to behavioral studies claiming a less asymmetrical representation of L2 relative to L1 (Hull and Vaid 2007), the model posits that both L1 and L2 language systems, in right-handed bilinguals, are entirely represented in the LH (Paradis 2003; 2009).

These postulations give rise to three hypotheses on the neuroanatomical organization of translation routes. First, given that both the L1 and the L 2 vocabularies are represented in declarative memory networks, word translation can be reasonably proposed to rely critically on relevant areas. This leads to the prediction that word translation skills should be more significantly impaired in posterior than in frontobasal patients.

Second, on the double assumption that (i) the grammar of at least one language (L1) is represented in frontobasal structures, and that (ii) processing of (non-rotely learned) sentences necessarily engages the grammatical systems of both the SL (for parsing) and the TL (for syntactic structuring), the hypothesis can be entertained that sentence translation is critically subserved by the abovementioned areas. This hypothesis predicts that patients with frontobasal lesions will be significantly more impaired in sentence than in word translation. 
Finally, as both $\mathrm{L} 1$ and $\mathrm{L} 2$ are represented in the $\mathrm{LH}$, it can be hypothesized that translation routes are left-lateralized. This is an interesting hypothesis in that it contradicts previous studies proposing that the right hemisphere $(\mathrm{RH})$ is crucially involved in language processing during translation (Fabbro, Gran et al. 1990; 1991; Gran and Fabbro 1991). If the present hypothesis is correct, translation neuropathologies should occur predominantly as a result of LH damage.

\section{Translation disorders due to brain lesions: A comprehensive review}

To date, four different neuropathologies have been documented that disturb translation skills in bilinguals. They are known as compulsive translation, inability to translate, paradoxical translation behavior, and translation without comprehension. Available anecdotal, qualitative, and quantitative evidence for each is next offered in separate subsections. While not present in the original publications, statistical analyses are provided for all reports offering quantitative data, except those where raw and mean scores were so low as to render further analysis superfluous. To this end, $2 \times 2$ contingency tables (quantifying correct and incorrect responses per task) were used in combination with Chi-square tests (with Yates correction). However, integrative meta-analysis across studies was not possible, given that methodological differences among them precluded statistical comparisons. This limitation notwithstanding, functional and neuroanatomical dissociations can be firmly established by considering overall patterns as revealed by raw/mean scores or qualitative observations across case studies, even in the absence of statistical validation. For examples, see the works of Paradis $(1977 ; 1989)$ on bilingual aphasia, and Capitani, Laiacona et al. (2003) on semantic category-specific deficits.

The sample comprised 21 bilingual/multilingual patients (15 male, 6 female), ranging from 15 to 91 years old (two below 25, ten between 40 and 65, six over 65, three unknown). They spoke various combinations of languages. All were either confirmed or presumed to be right-handers. Most of them presented focal lesions, resulting from varied etiologies. Nineteen were diagnosed with some stable or transient form of aphasia, whereas one suffered from presenile dementia and another one presented with a sociolinguistic disorder. All exhibited linguistic dysfunctions, including anomia, language mixing, and disfluency. However, other intellectual faculties, such as memory, attention, and visuospatial skills, were virtually intact in all cases. Additional demographic, clinical, and language-history data for each patient are provided in the Appendix.

\subsection{Compulsive translation}

Compulsive translation consists in the immediate, involuntary translation of utterances. This behavior is often accompanied by an inability to translate willingly. Perecman (1984) suggested that it may be caused by a conceptual dysfunction. However, it may also reflect an impairment of language-inhibition mechanisms (Green 1986).

The first report corresponds to patient D.O. (Kauders 1929), a trilingual who spoke German (L1), French (L2), and English (L3). D.O. suffered an apoplexy which focally damaged left temporal and parietal areas. Comprehension was disrupted in 
all three languages, while speech was unintelligible and characterized by language mixing. When asked to name objects in L1, D.O. would first translate the target word into his other two languages and only then produce the L1 word. For example, when asked to name the color of a yellow figure, D.O. responded "yellow... jaune... gelb."

Patient Ch. (Veyrac 1931), a speaker of English (L1) and French (L2), suffered a stroke resulting in Broca's aphasia. Although voluntary speech and translation were impossible, Ch. would compulsively translate utterances from L1 to L2. For example, when asked "What time is it?" the patient responded "Quelle heure est-il?" Similar patterns were observed in the frontal patients described by Stengel and Zelmanowitz (1933) and Weisenberg and McBride (1935).

Further anecdotal evidence was offered by Jakobson (1964). After a left-sided cranial trauma, he spent hours compulsively translating his own utterances into five different languages. A similar dysfunction was observed in the multilingual aphasic described by Schulze (1968).

Perecman (1984) reported the case of H.B., a trilingual (L1: German, L2: French, L3: English) who suffered bilateral temporal damage. The patient would mix languages and compulsively translate sentences from L1 into L3 (e.g., "verstehen sie Deutsch... do you know German [...] verstehen sie Deutsch... aber nur ein bischen... but only a little"). Yet, voluntary translation was severely compromised.

Patient N.T. (De Vreese, Motta et al. 1988) was a multilingual with Alzheimer's disease, featuring severe temporal damage. Instances of compulsive translation were observed from L1 (Italian) into L2 (French), L3 (English), and L4 (German) (e.g., "Questa è una pipa, this is a pipe;" "Mattino, c'est matin ça;" "Arrivederci, auf Wiedersehen"). There were no signs of monolingual echolalia, and voluntary translation was possible only from L1 into L2.

Lebrun (1991) documented an atypical case. Following RH damage, the patient would compulsively translate written words and full texts, in the absence of oral aphasia. For Lebrun (1991), this behavior reflects an inability to follow sociolinguistic conventions.

Patient R.K. (Eviatar, Leikin et al. 1999) suffered a stroke damaging the basal ganglia and the corona radiata of her LH. She was diagnosed with fluent aphasia, dysgraphia, and dyslexia in both her languages. Although on-demand translation was completely abolished, she engaged in compulsive translation during lexicalassociation and antonym-generation tasks.

Recently, García-Caballero, García-Lado et al. (2007) described the case of an elderly crossed aphasic. After a cerebral infarction compromising her RH's basal ganglia, the patient could no longer produce L1 utterances voluntarily. Comprehension was impaired in both her languages. In L1 lexeme-repetition tasks, she would compulsively translate her responses into L2. Voluntary translation was possible only in the L2-L1 direction.

In sum, compulsive translation results mainly from posterior LH lesions, and it can occur in both directions, regardless of whether the target language is available for spontaneous production. A summary of data and additional information for each patient can be found in Table 3 (see Appendix). 


\subsection{Inability to translate}

Inability to translate involves a severe or complete incapacity to voluntarily translate utterances in one or both directions. Some patients suffering from compulsive translation found it difficult or impossible to translate on demand. For example, when patient H.B. was asked to translate the stimuli "essen," "the wall," and "Seife," he responded "English," "la val est langue française," and "Französiche Auskunft," respectively. In the case of R.K., on-demand word translation was described as impossible in both directions.

Gastaldi (1951) documented the case of a bilingual aphasic suffering from chronic inflammation in his LH. Whereas object-naming was spared in both languages, BT and FT of words proved impossible. Also, his spontaneous speech skills were reduced.

Byng, Coltheart et al. (1984) reported the case of B., a dyslexic child with severe focal damage to his left parietal and temporal lobes. His out-loud reading skills were normal in L2 (English) but very poor in L1 (Nepalese). A sight-translation test revealed a dissociation between FT (72\%) and BT (0\%). This difference was statistically significant, $\chi^{2}(1, N=50)=25.08, p<0.001$. Some of his mistakes were semantic in nature (e.g., he translated the Nepalese word for horse as duck).

Patient A.S. (Nilipour and Ashayeri 1989) spoke Farsi (L1), English (L2), and German (L3). He was involved in an explosion causing severe frontotemporal trauma. For over a month, he presented alternating antagonism between L1 and L3 (when one language was available for spontaneous production, the other was not). Accuracy in word translation was $10 \%$ in L1-L2, $20 \%$ in L2-L1, 0\% in L1-L3, and 50\% in L3-L1. Sentence translation skills were completely lost, although SL comprehension was intact. Some of the patient's mistakes in BT were semantic paraphasias (e.g., Fahrrad was translated by the Farsi word meaning car).

Aglioti and Fabbro (1993) reported the case of E.M., a Venetian (L1) and Italian (L2) speaker. After a stroke, E.M. presented an ischemic lesion to her left basal ganglia. L1 verbal production was abolished, but her L2 remained functional. Comprehension was well preserved in both languages. E.M. performed three translation tasks, all revealing significant differences between FT and BT. Results for these directions were $69 \%$ vs. $41 \%$ in oral word translation $\left(\chi^{2}(1, N=150)=10.78, p=0.001\right), 95 \%$ vs. $5 \%$ in written word translation $\left(\chi^{2}(1, N=40)=28.9, p<0.001\right)$, and $72 \%$ vs. $35 \%$ in oral sentence translation $\left(\chi^{2}(1, N=150)=19.52, p<0.001\right)$, respectively.

Fabbro and Paradis (1995) documented translation deficits in three other patients with left basal-ganglia damage, namely, C.B., El.M. and O.R. Like E.M., they had greater impairments in their L1s than in their non-native languages. Their translation skills were assessed with Part C of the BAT.

C.B., a 71-year-old trilingual (L1: Friulian, L2: Italian, L3: English), suffered an ischemic stroke damaging her left basal ganglia. She was unable to translate words from L3 into L1, and sentences in both directions between L1 and L3 and between L2 and L3. However, SL comprehension was spared. Her performance attests to the functional independence of BT relative to FT, since her added scores for word translation from L2 and L3 into L1 (25\%) were significantly lower than those for word translation from L1 into L2 and L3 (52\%), $\left.\chi^{2}(1, N=40)=8.1, p<0.01\right)$. Collapsing all language pairs and directions, the patient performed significantly better on word $(43 \%)$ than on sentence $(11 \%)$ translation, $\chi^{2}(1, N=96)=9.42, p<0.01$. 
El.M. was fluent in Friulian (L1) and Italian (L2). A hemorrhage caused a vast subcortical lesion compromising left basal-ganglia structures and producing nonfluent aphasia in both languages. His inability to translate sentences was virtually total in BT and FT. However, word translation skills were largely spared for both directions. Collapsing BT and FT, mean scores for word and sentence translation were $65 \%$ and $1 \%$, respectively $\left(\chi^{2}(1, N=32)=7.61, p<0.01\right)$, corroborating that these abilities are dissociable.

O.R., also a speaker of Friulian (L1) and Italian (L2), sustained severe left basalganglia damage subsequent to an ischemic stroke. While he remained fluent in both languages, he was unable to translate sentences (16\% accuracy in each direction). Word translation was better from L1 into L2 (90\%) than in the opposite direction (40\%). This difference, however, did not reach statistical significance, $\chi^{2}(1, N=20)=$ $3.51, p>0.05$. Word translation (65\%) was significantly less compromised than sentence translation $(17 \%), \chi^{2}(1, N=32)=5.22, p<0.05$.

In discussing the last four cases, Fabbro and Paradis (1995) observe that left basal-ganglia structures may play an important role in translation, and that the routes supporting BT and FT may be independently damaged. However, they overlook other interesting patterns in the data. In these frontobasal patients: (i) BT is more significantly impaired than FT for both word $\left(\chi^{2}(1, N=210)=10.58, p=0.001\right)$ and sentence $\left(\chi^{2}(1, N=186)=16.93, p<0.001\right)$ translation; (ii) collapsing both directions, sentence translation (46\%) is more significantly compromised than word translation (61\%), $\chi^{2}(1, N=396)=7.42, p<0.01$; and (iii) the advantage of word translation over sentence translation is greater in BT than in FT (mean differences being 19\% and 10\%, respectively).

Finally, Weekes and Raman (2008) reported the case of B.R.B., a bilingual (L1: Turkish, L2: English) who suffered a stroke producing severe left parieto-occipital damage. He exhibited deep dysphasia, with fluent but semantically empty spontaneous speech in both languages. Translation tests were administered only in BT. A first examination revealed a marked inability to translate verbs and verbal nouns, with greater deficits in oral than in sight translation. A second test corroborated the dissociation between oral (5\%) and sight $(93 \%)$ translation, $\chi^{2}(1, N=84)=61.74, p<0.001$. These deficits cannot be attributed to auditory or production deficits, given the high scores on L2 auditory lexical decision (100\%), repetition ( $\mathrm{L} 1=82 \%, \mathrm{~L} 2=65 \%$ ), word reading $(\mathrm{L} 1=100 \%, \mathrm{~L} 2=85 \%)$, and picture naming $(\mathrm{L} 1=72 \%, \mathrm{~L} 2=82 \%)$.

In conclusion, all these cases involve LH damage, and show that a single lesion may selectively compromise either BT or FT of both words and sentences, even if monolingual comprehension and production are spared. Additional patient data and a summary of the evidence can be found in Table 4 (see Appendix).

\subsection{Paradoxical translation behavior}

Paradoxical translation behavior is a rare pathology in which patients are capable of translating into a language unavailable for spontaneous production (e.g., L1), but incapable of translating into a language available for spontaneous production (e.g., L2).

The first two cases were described by Paradis, Goldblum et al. (1982). Patient A.D. was a nun who spoke French (L1) and Arabic (L2). She was hit by a car and 
suffered a left temporo-occipito-parietal contusion. Like patient A.S., she exhibited signs of alternating antagonism. For over a month, during the days when only her L2 was available for spontaneous production, she was able to translate into L1 but not into L2. When speech was possible in L1 but not in L2, only translation into L2 was possible. In a first evaluation, she was unable to describe a picture in L1. However, her BT skills were intact when administered single words (100\%) and sentences (100\%, with minor replacements of definite by indefinite articles). The following day, when her production skills improved in L1 and diminished in L2, she could translate only two out of the six Arabic sentences she had translated correctly the day before.

The second case concerns a Canadian patient (henceforth, C.P.) who spoke French (L1) and English (L2) fluently. He underwent surgery for removal of a venous malformation in his left temporo-parietal region. Until the edema disappeared, C.P. exhibited alternating antagonism. During a period when his L2 was more impaired than his L1, he was asked to translate six sentences in each direction. FT was flawless, but BT was virtually impossible despite perfect comprehension of all stimuli.

Paradoxical translation behavior was also observed in N.T. (De Vreese, Motta et al. 1988), who could communicate only in L1. His cumulative mean scores in sentence translation tests were 70\% from L2 into L1 and 20\% from L1 into L2. Translation was also virtually impossible between L1 and L3.

In short, this disorder indicates that the ability to engage in BT or FT does not depend on the integrity of the routes supporting L1 or L2 production, respectively; and that BT may be possible when FT is severely impaired, and vice versa. Table 5 (see Appendix) offers a summary of findings and additional patient data.

\subsection{Translation without comprehension}

Patients exhibiting translation without comprehension are able to translate utterances correctly although they are unaware of the meaning of the SL expressions. Patient Ch. (Veyrac 1931) provided the first examples of this disorder. Although she translated stock phrases compulsively and accurately, she never gave signs of comprehending the commands she received.

Patient C.P. had similar symptoms. On a day in which he was more fluent in French than in English, he was asked to translate words such as "plafond," "porte," and "fenêtre." He accurately provided the English equivalents, but was unable to identify those objects in the room. Likewise, the authors who studied N.T. affirm that

[the patient] displayed a similar behaviour as the second case reported by Paradis, Goldblum et al. (1982). When asked to point to pictured objects given their Italian names, he correctly translated the words in French although he often remained unable to point to their respective pictures. (De Vreese, Motta et al. 1988: 253)

All in all, this pathology occurs subsequent to posterior LH lesions, and suggests that the perceptual and conceptual representations associated with SL words need not be active during translation. Further detail on these cases is provided in Table 6 (see Appendix). 


\section{Discussion: A hypothesis-driven interpretation of the evidence}

\subsection{Neurofunctional hypotheses}

Hypothesis 1 predicted a dissociation between the routes supporting lexical translation and those subserving L1 or L2 production. Confirmatory evidence is found in the cases of inability to translate and paradoxical translation behavior. The routes supporting BT can remain functional when those involved in L1 production are impaired (A.D., C.P.), and vice versa (A.D., C.P., O.R., N.T., R.K.). Conversely, the routes supporting FT can remain functional when those involved in L2 production are impaired (A.D., N.T., E.M., C.B., and Ch.), and vice versa (A.D., O.R., R.K., and the patient in Gastaldi (1951)). Further support is offered by Borius, Giussani et al. (2012), who showed that inhibition of specific cortical sites in the bilingual brain can impair L1 or L2 production without compromising translation processes.

According to hypothesis 2, the routes supporting BT and FT are mutually independent. This is also corroborated by the cases of inability to translate and paradoxical translation behavior. These show that the neural networks responsible for BT can remain functional when those supporting FT are inhibited or destroyed (A.S. and A.D.), and vice versa (B., E.M., C.B., O.R., A.D., C.P., and N.T.). Neuroimaging studies provide additional evidence. In a word translation task, Klein, Milner et al. (1995) showed that the left putamen was active during FT but not during BT. Quaresima, Ferrari et al. (2002) fMRI study on sentence translation revealed differential activation patterns for each direction in sites adjacent to Broca's area. Wider activation patterns for FT relative to BT were also shown by Kurz (1995) and Rinne, Tommola et al. (2000). These results, too, indicate that there are specific neural circuits which participate only in one translation direction. In this sense, the cases presented by Fabbro and Paradis (1995) suggest that basal ganglia circuits are more crucial for BT than FT.

Hypothesis 3 postulates that translation can be performed through either a lexical route or a conceptually-mediated route. The cases of translation without comprehension provide confirmatory evidence: TL equivalents for SL expressions can be found even when relevant conceptual representations cannot be accessed. Furthermore, a double dissociation may be postulated between A.S. and C.B. (who were able to understand SL expressions but could not translate them) and Ch., C.P., and N.T. (who were capable of translating SL expressions without comprehending them). Evidence for conceptual involvement during translation is found in patients A.S. and B., some of whose translation errors involved semantic paraphasias (e.g., translating the Nepalese word for "horse" as "duck"). Insofar as these paraphasias engage the semantic system, they reflect conceptually-mediated translation processes.

\subsection{Neuroanatomical hypotheses}

Hypothesis 4 claims that posterior areas implicated in declarative memory are specialized for word (as opposed to sentence) translation. The evidence seems to support this postulate. First, compulsive translation in patients with lesions to declarative memory networks involves mainly words and lexemes. Spontaneous translation of non-rotely learned sentences was observed only subsequent to bilateral lesions (H.B.). ${ }^{4}$ Second, in five out of seven reports of compulsive translation including neuroana- 
tomical references, the damage was confined to left temporal/temporo-parietal areas. The other two patients (Weisenberg and McBride 1935; García-Caballero, GarcíaLado et al. 2007), with frontal lesions, were better than these five on word translation. Third, frontobasal patients were either largely or completely unimpaired in word translation in specific directions (E.M., C.B., El.M., O.R.). There are no reports in which word translation became impossible subsequent to frontobasal lesions. On the contrary, word translation did prove impossible for some posterior patients. Additional evidence comes from a neuroimaging study showing that word translation differentially engages temporal lobe structures (Klein, Milner et al. 1995).

Hypothesis 5 posits that sentence (as opposed to word) translation relies critically on procedural memory circuits. The strongest evidence comes from patients E.M., C.B., El.M., and O.R. (all with basal-ganglia lesions), who were more significantly impaired in sentence than in word translation. Also, the frontobasal crossed aphasic described by García-Caballero, García-Lado et al. (2007) was capable of translating words but not sentences. Furthermore, the only two neuroimaging studies on sentence translation recording the whole brain revealed distinctive activation increases in frontal (but not in posterior) regions (Lehtonen, Laine et al. 2005; HervaisAdelman, Moser-Mercer et al. 2011).

Finally, hypothesis 6 predicts that translation routes are left-lateralized. In 18 out of 21 cases reviewed, translation disorders resulted from lesions damaging the $\mathrm{LH}$ only. Patient H.B. sustained bilateral lesions. The other two sustained RH damage, but they do not necessarily contradict the hypothesis. First, the patient in GarcíaCaballero, García-Lado et al. (2007) was a crossed aphasic, which means that her RH was subserving the language functions typically subserved by the LH. Second, Lebrun (1991) described his patient's disorder as a sociolinguistic deficit. Although sociolinguistic abilities do play a role in translation, they are not part of translation routes per se. As stated in Section 2, previous studies have shown $\mathrm{RH}$ involvement during translation. However, this does not mean that translation routes themselves have a bilateral distribution. Instead, RH participation likely reflects the use of attentional, pragmatic, and otherwise extralinguistic strategies (Paradis 2003; 2009). Such processes, arguably related to what Lebrun (1991) termed sociolinguistic skills, are distinct and separate from those subserved by translation routes proper. Additional evidence comes from several neuroimaging studies showing that the $\mathrm{LH}$ is either exclusively or predominantly involved in word, sentence, and supra-sentential text translation (García 2013).

\section{Implications for understanding professional translation within Translation Studies}

\subsection{What do controlled, atomistic tasks reveal about real-life translation?}

Most of the evidence presented comes from cerebral patients performing controlled tasks with decontextualized stimuli. Admittedly, this scenario hardly reflects the real-life complexities of translation as a purposeful, text-based activity. Some scholars in the field (e.g., Lederer 1978/2002) detract from the value of experimental research, describing it as artificial and even unnecessary to understand cognitive aspects of translation. Contrariwise, Gile (1990) and Moser-Mercer (1994) contend 
that interdisciplinary experiments are indispensable to foster progress in Translation Studies. This paper reflects the latter position.

Scholars such as Moser-Mercer (2010), Diamond and Shreve (2010), and Tymoczko (2012) have also advanced theoretical views on translation by interpreting results of neuroscientific experiments with non-translators (and even non-human animals). For instance, Diamond and Shreve (2010) review various neuroimaging and neurophysiological studies involving non-translation tasks (e.g., word reading, language switching) to discuss critical aspects of translation. Similarly, Tymoczko (2012) extrapolates findings from visual perception and memory studies to reflect on nonconscious decisions during translation and their impact on target audiences.

Like these studies, the present paper does not reveal the neural basis of translation in all its complexity, but it does offer important theoretical insights. For example, the data indicates that different translation units (words vs. sentences) call for different neurocognitive mechanisms. This finding questions the pertinence of models which assume that cognitive translation processes can be explained by reference to a single translation unit - e.g., the simple clause, in Bell (1991) -, or which recognize the existence of different units but fail to formally characterize processing differences among them (Hurtado Albir 1990).

More generally, the use of decontextualized stimuli in controlled settings is not irrelevant to explore translation processes. Prima facie, it might seem that single-word translation tasks are so atomistic that they are uninformative to understand actual translation practice. However, professional translators/interpreters daily face projects in which they process single-word units (e.g., list items, titles, captions, labels). As Christoffels, De Groot et al. (2003: 202) argue in reference to simultaneous interpreting, "[a]lthough the interpreter usually does not attempt to literally translate each word from the source language into the target language, some literal word-to-word translation is likely to play a role." Also, exploring word-translation mechanisms sheds light on lexical retrieval, which is a necessary component of all skopos-driven translation acts. At the very least, researching single-word translation provides information about the form-based route, which has been widely acknowledged in the literature (e.g., Massaro and Shlesinger 1997; Bajo, Padilla et al. 2000; De Groot 2000) and has been claimed to be preferred by professionals during periods of fatigue or stress (Darò and Fabbro 1994).

Finally, these findings are relevant for Translation Studies as a research field. The observation that basal-ganglia structures (involved in procedural memory) are critical for BT and FT of sentences invites research on the role of subcortical structures in translation. This also suggests that strictly linguistic processes (as opposed to executive or pragmatic functions) during translation involve an interplay of automatic and controlled mechanisms represented in procedural and declarative memory, respectively.

\subsection{Can these dissociations be presumed real even for professional translators?}

This paper assumes that the independence of different translation routes (hypotheses 1,2, and 3) and their neuroanatomical loci (hypotheses 4, 5, and 6) are not modified by translation experience. Such a position is not unwarranted. First, there seems to 
be no evidence against this claim, so it can be reasonably adopted as a null hypothesis. Second, some of the present hypotheses have been corroborated in studies with expert translators/interpreters. For example, the notions that translation routes are left-lateralized (hypothesis 6) and that there are neural networks which participate in only one translation direction (hypothesis 2) have been independently confirmed in PET studies with non-translators (Klein, Milner et al. 1995) and professional interpreters (Rinne, Tommola et al. 2000). ${ }^{5}$ Also, the experiment conducted by Borius, Giussani et al. (2012) with subjects possessing considerable translation experience showed that the stimulation of certain cortical sites impaired monolingual processes (naming and reading) but not translation skills. This supports the conclusion that "the process of translation must use neurocognitive pathways spatially distinct from these sites which have been identified as involved in reading or naming" (Borius, Giussani et al. 2012: 620), which is consistent with hypothesis 1. Finally, from a theoretical stance, Paradis (2009) argues that form-based and conceptual routes (hypothesis 3) exist in the brains of both professional and occasional translators, although these may differ in their reliance on each route.

However, translation expertise surely impacts on some aspect of the bilingual brain. Several studies (e.g., Fabbro, Gran et al. 1990; 1991; Proverbio, Adorni et al. 2009; Proverbio and Adorni 2011) indicate more bilateral brain activity during verbal processes in professionals than in non-translators. Nevertheless, increased RH participation in the former group probably reflects greater reliance on attentional and pragmatic strategies; it does not mean that strictly linguistic functions, such as the ones studied herein, have ceased to be left-lateralized (Paradis 2003; 2009). For their own part, Elmer, Meyer et al. (2010) used the evoked response potentials (ERP) technique to explore whether interpreting expertise produces neuronal adaptations. They asked non-translators and professional interpreters (specialized in BT) to decide whether noun pairs were semantically congruent or incongruent. The pairs were presented in four conditions: (i) L1-L1, (ii) L2-L2, (iii) L1-L2, (iv) L2-L1. The results showed enlarged $\mathrm{N} 400$ responses for the interpreters in all conditions but (iv), namely, the one corresponding to the direction professionally practiced. Since the N400 component is systematically modulated by semantic-level activity, the authors suggest that translation-specific training induces changes in sensitivity to lexico-semantic processing within and across languages. ${ }^{6}$ In sum, these translation-expertise effects concern the involvement of neural circuitry subserving non-linguistic functions and the electrochemical processes underlying signal transmission along neural pathways. They do not imply changes in the functional independence or the neuroanatomical location of the translation routes.

\section{Limitations and directions for future study}

The present conclusions must be taken with reserve. Although the overall patterns identified support the hypotheses, not all reports offer extensive, detailed information. Some provide only qualitative or anecdotal data on the patients' impairments, while others lack precise descriptions of lesion site and etiology. The latter point is important, for signal transmission along neural pathways may be differentially altered by upstream and downstream disruptions, resulting from either traumatic injury or vascular damage. Also, the reduced number of trials in most of the tasks 
surveyed weakens the statistical validation of the results. Finally, some of the disorders documented may partly reflect non-linguistic deficits, such as pragmatic or control-related difficulties.

These limitations can be circumvented in future research. The neurofunctional hypotheses can be tested through behavioral and neurophysiological studies, with both patients and healthy subjects, involving comparisons among L1 and L2 production tasks (e.g., picture naming) and translation tasks in both directions. Statistical data could thus be obtained to corroborate the significance of the observed dissociations. Moreover, the use of high-resolution techniques could provide data on the existence of neural networks differentially devoted to translation, as opposed to monolingual production; or BT, as opposed to FT.

As regards the neuroanatomical hypotheses, PET and $\mathrm{fMRI}$ experiments geared towards the detection of differential activity patterns for word and sentence translation may provide more refined data on the relevant brain areas. Only a few translation experiments have used such techniques, and none has explored this dissociation. Research along these lines could increase our understanding of which cognitive mechanisms are engaged by each translation unit.

\section{Conclusion}

The study of neural translation routes is still incipient. The present review has offered evidence for six hypotheses predicting neurofunctional and neuroanatomical dissociations for translation-specific routes. Further behavioral and neuroimaging studies are required to test the hypotheses in both neurotypical and brain-damaged subjects. This line of research may open exciting avenues for Translation Studies at large.

\section{ACKNOWLEDGMENTS}

This research was supported by the National Scientific and Technical Research Council, Argentina.

\section{NOTES}

1. A similar dissociation was proposed by Paradis (1984) upon consideration of translation disorders in a single case of bilingual aphasia.

2. Ditto note 1 .

3. A similar hypothesis was proposed by Paradis (1994b), upon observing peculiar deficits in a single case of bilingual aphasia.

4. Further research is necessary to account for this discrepant pattern, which may involve multiple factors, such as etiology (hematoma), lesion site and extension, and lateralization (the patient's manual preference is not reported).

5. This comparison must be taken with reserve since the studies involved different translation units and control conditions.

6. For further insights into the neurophysiological correlates interpreting expertise, see Moser-Mercer (2010).

\section{REFERENCES}

Aglioti, Salvatore and Fabbro, Franco (1993): Paradoxical selective recovery in a bilingual aphasic following subcortical lesions. NeuroReport. 4:1359-1362.

Bajo, María, Padilla, Francisca and Padilla, Presentación (2000): Comprehension processes in simultaneous interpreting. In: Andrew Chesterman, Natividad Gallardo San Sal- 
vador and Yves Gambier, eds. Translation in Context. Amsterdam: John Benjamins, 127-142.

BELL, Roger (1991): Translation and Translating. London: Longman.

Borius, Pierre-Yves, Giussani, Carlo, Draper, Louisa, et al. (2012): Sentence translation in proficient bilinguals: A direct electrostimulation brain mapping. Cortex. 48:614-622.

Byng, Sally, Coltheart, Max, Masterson, Jacqueline, et al. (1984): Bilingual biscriptal deep dyslexia. The Quarterly Journal of Experimental Psychology. 36(3):417-433.

Braver, Todd, BARch, Deanna, Kelley, William, et al. (2001): Direct comparison of prefrontal cortex regions engaged by working and long-term memory tasks. Neuroimage. 14:48-59.

Capitani, Erminio, Laiacona, Marcella, Mahon, Bradford, et al. (2003): What are the facts of semantic category-specific deficits? A critical review of the clinical evidence. Cognitive Neuropsychology. 20(3/4/5/6):213-261.

Chee, Michael, Soon, Chun and LeE, Hwee (2003): Common and segregated neuronal networks for different languages revealed using functional magnetic resonance adaptation. Journal of Cognitive Neuroscience. 15:85-97.

Christoffels, Ingrid, DE Groot, Annette and Waldorp, Lourens (2003): Basic skills in a complex task: A graphical model relating memory and lexical retrieval to simultaneous interpreting. Bilingualism: Language and Cognition. 6(3):201-211.

Damasio, Antonio (1994): Descartes' Error: Emotion, Reason, and the Human Brain. London: Penguin.

Darò, Valeria and Fabbro, Franco (1994): Verbal memory during simultaneous interpretation: Effects of phonological interference. Applied Linguistics. 15:365-381.

DE Groot, Annette (2000): A complex-skill approach to translation and interpreting. In: Sonja TirkKonen-Condit and Ritta JäÄskeläinen, eds. Tapping and Mapping the Processes of Translation and Interpreting. Amsterdam: John Benjamins, 53-68.

De Vreese, Luc, Мотta, Massimo and Toschi, Andrea (1988): Compulsive and paradoxical translation behaviour in a case of presenile dementia of the Alzheimer type. Journal of Neurolinguistics. 3(2):233-259.

Diamond, Bruce and Shreve, Gregory (2010): Neural and physiological correlates of translation and interpreting in the bilingual brain: Recent perspectives. In: Gregory SHREVE and Erik Angelone, eds. Translation and Cognition. Amsterdam/Philadelphia: John Benjamins, 289-322.

Elmer, Stefan, Meyer, Martin and JAncke, Lutz (2010): Simultaneous interpreters as a model for neuronal adaptation in the domain of language processing. Brain Research. 1317:147-156.

Eviatar, Zohar, Leikin, Marc and Ibrahim, Raphiq (1999): Phonological processing of second language phonemes: A selective deficit in a bilingual aphasic. Language Learning. 49(1):121141.

Fabbro, Franco (1999): The Neurolinguistics of Bilingualism: An Introduction. Hove, Sussex: Psychology Press.

FABBro, Franco (2001): The bilingual brain: Cerebral representation of languages. Brain and Language. 79:211-222.

Fabbro, Franco and Paradis, Michel (1995): Differential impairments in four multilingual patients with subcortical lesions. In: Michel Paradis, ed. Aspects of Bilingual Aphasia. Oxford: Pergamon, 139-176.

Fabbro, Franco, Gran, Laura, Basso, Gianpaolo, et al. (1990): Cerebral lateralization in simultaneous interpretation. Brain and Language. 39(1):69-89.

FabBro, Franco, Gran, Bruno and Gran, Laura (1991): Hemispheric specialization for semantic and syntactic components of language in simultaneous interpreting. Brain and Language. 41:1-42.

Fabbro, Franco, Skrap, Miran and Aglioti, Salvatore (2000): Pathological switching between languages following frontal lesion in a bilingual patient. Journal of Neurology, Neurosurgery, and Psychiatry. 68:650-652. 
French, Robert and JACQUet, Maud (2004): Understanding bilingual memory: Models and data. Trends in Cognitive Science. 8(2):87-93.

GARcía, Adolfo (2013): Brain activity during translation: A review of the neuroimaging evidence as testing ground for clinically-based hypotheses. Journal of Neurolinguistics. 26(3):370-383.

García-Caballero, Alejandro, García-Lado, Isabel, González-Hermida, Javier, et al. (2007): Paradoxical recovery in a bilingual patient with aphasia after right capsuloputaminal infarction. Journal of Neurosurgical Psychiatry. 78:89-91.

Gastaldi, Guido (1951): Osservazioni su un afasico bilingüe. Sistema Nervoso. 2:175-180.

GILE, Daniel (1990): Scientific research vs. personal theories in the investigation of interpretation. In: Laura GrAN and Christopher TAYLOR, eds. Aspects of Applied and Experimental Research on Conference Interpretation. Udine: Campanotto, 28-41.

Gran, Laura and FabBro, Franco (1991): A dichotic-listening study on error recognition among professional interpreters. In: Miladen Jovanovic, ed. Proceedings of the XII World Congress of FI. Belgrade: Prevodilac, 564-572.

Green, David (1986): Control, activation, and resource: A framework and a model for the control of speech in bilinguals. Brain and Language. 27:210-223.

Green, David (2005): The neurocognition of recovery patterns in bilingual aphasics. In: Judith Kroll and Annette DE Groot, eds. Handbook of Bilingualism: Psycholinguistic Approaches. Oxford: Oxford University Press, 516-530.

Hernandez, Arturo (2009): Language switching in the bilingual brain: What's next? Brain and Language. 109:133-140.

Hervais-Adelman, Alexis, Moser-Mercer, Barbara, Michel, Christoph, et al. (2011): The neural basis of simultaneous interpretation: A functional magnetic resonance imaging investigation of novice simultaneous interpreters. Poster presented at the Eighth International Symposium on Bilingualism, Oslo, 15-18 June 2011.

Hull, Rachel and VAID, Jyotsna (2007): Bilingual language lateralization: A meta-analytic tale of two hemispheres. Neuropsychologia. 45:1987-2008.

Hurtado Albir, Amparo (1990): La notion de fidélité en traduction. Paris: Didier.

Hurtado Albir, Amparo (2001): Traducción y Traductología: introducción a la traductología. Madrid: Cátedra.

Ijalba, Elizabeth, Obler, Loraine and Chengappa, Shymala (2004): Bilingual aphasia. In: Tej Bathia and William Ritchie, eds. The Handbook of Bilingualism. Malden: Blackwell, 71-89.

Jakobson, Roman (1964). Discussion. In: A. V. S. DeReuck and Maeve O'Conner, eds. Disorders of Language. Boston: Little, Brown, 120.

Janyan, Armina, Popivanov, Ivo and Andonova, Elena (2009): Concreteness effect and word cognate status: ERPs in single word translation. In: Kai Alter, Merle Horne, Magnus LINDGREN, et al., eds. Brain Talk: Discourse with and in the Brain. Lund: Lunds Universitet, 21-30.

KAUDERs, Otto (1929): Über polyglotte Reaktionen bei einer sensorischen Aphasie. Zeitschrift für die gesamte Neurologie und Psychiatrie. 149:291-301.

Klein, Denise, Milner, Brenda, Zatorre, Robert, et al. (1995): The neural substrates underlying word generation: A bilingual functional-imaging study. Proceedings of the National Academy of Science of the United States of America. 92(7):2899-2903.

Klein, Denise, Zatorre, Robert, Chen, Jen-Kai, et al. (2006): Bilingual brain organization: A functional magnetic resonance adaptation study. NeuroImage. 31:366-375.

Kroll, Judith and Stewart, Erika (1994): Category interference in translation and picture naming: Evidence for asymmetric connections between bilingual memory representations. Journal of Memory and Language. 33:149-174.

Kroll, Judith, van Hell, Janet, Tokowicz, Natasha, et al. (2010): The Revised Hierarchical Model: A critical review and assessment. Bilingualism: Language and Cognition. 13:373-381.

KURZ, Ingrid (1995): Watching the brain at work - An exploratory study of EEG changes during simultaneous interpreting (SI). The Interpreters' Newsletter. 6:3-16. 
Lebrun, Yves (1991): Polyglotte Reaktionen. Neurolinguistik. 5:1-9.

LEDERER, Marianne (1978/2002): Simultaneous interpretation - Units of meaning and other features. In: Franz Pöchнаскеr and Miriam Shlesinger, eds. The Interpreting Studies Reader. London/New York: Routledge, 131-140.

Lehtonen, Minna, Laine, Matti, Niemi, Jussi, et al. (2005): Brain correlates of sentence translation in Finnish-Norwegian bilinguals. NeuroReport. 16(6):607-610.

Malakoff, Marguerite (1992): Translation ability: A natural bilingual and metalinguistic skill. In: Richard Jackson Harris, ed. Cognitive Processing in Bilinguals. Amsterdam: North Holland, 515-529.

Massaro, Dominic and Shlesinger, Miriam (1997): Information processing and a computational approach to the study of simultaneous interpretation. Interpreting. 2:13-53.

Moser-Mercer, Barbara (1994): Paradigms gained or the art of productive disagreement. In: Sylvie Lambert and Barbara Moser-Mercer, eds. Bridging the Gap: Empirical Research in Simultaneous Interpretation. Amsterdam: John Benjamins, 17-23.

Moser-Mercer, Barbara (2010): The search for neuro-physiological correlates of expertise in interpreting. In: Gregory Shreve and Erik Angelone, eds. Translation and Cognition. Amsterdam/Philadelphia: John Benjamins, 263-288.

Nilipour, Reza and Ashayeri, Hassan (1989): Alternating antagonism between two languages with successive recovery of a third in a trilingual aphasic patient. Brain and Language. 36:23-48.

Ojemann, George and Whitaker, Harry (1978). The bilingual brain. Archives of Neurology. 35:409-412.

Paradis, Michel (1977): Bilingualism and aphasia. In: Haiganoosh Whitaker and Harry Whitaker, eds. Studies in Neurolinguistics. Vol. 3. New York: Academic Press, 65-121.

Paradis, Michel (1979): L'Aphasie chez les bilingues et les polyglottes. In: André Lecours and François L'hermitte, eds. L’Aphasie. Paris: Flammarion, 605-616.

Paradis, Michel (1984): Aphasie et traduction. Meta. 29:57-67.

PARAdis, Michel (1989): Bilingual and polyglot aphasia. In: François Boller and Jordan GrafMAN, eds. Handbook of Neuropsychology. Vol. 2. Amsterdam: Elsevier, 117-140.

PARADIs, Michel (1994a): Neurolinguistic aspects of implicit and explicit memory: Implications for bilingualism. In: Nick ElLIs, ed. Implicit and Explicit Learning of Second Languages. London: Academic Press, 393-419.

PARAdIs, Michel (1994b): Towards a neurolinguistic theory of simultaneous translation: The framework. International Journal of Psycholinguistics. 10,3(29):319-335.

PARAdIs, Michel (2003): The bilingual Loch Ness monster raises its non-asymmetric head again - or, why bother with such cumbersome notions as validity and reliability? Comments on Evans et al. (2002). Brain and Language. 87:441-448.

Paradis, Michel (2004): A Neurolinguistic Theory of Bilingualism. Amsterdam: John Benjamins.

PARADIs, Michel (2009): Declarative and Procedural Determinants of Second Languages. Amsterdam: John Benjamins.

Paradis, Michel, Goldblum, Marie-Claire and Abidi, Raouf (1982): Alternate antagonism with paradoxical translation behavior in two bilingual aphasic patients. Brain and Language. 15:55-69.

Perecman, Ellen (1984): Spontaneous translation and language mixing in a polyglot aphasic. Brain and Language. 23:43-63.

PöchHACKeR, Franz (2004): Introducing Interpreting Studies. New York: Routledge.

Price, Cathy, Green, David and von Studnitz, Roswitha (1999): A functional imaging study of translation and language switching. Brain. 122:2221-2235.

Proverbio, Alice, Adorni, Roberta and Zani, Alberto (2009): Inferring native language from early bio-electrical activity. Biological Psychology. 80:52-63.

Proverbio, Alice and Adorni, Roberta (2011): Hemispheric asymmetry for language Processing and lateral preference in simultaneous interpreters. Psychology. 2(1):12-17. 
Quaresima, Valentina, Ferrari, Marco, van der Slujis, Marco, et al. (2002): Lateral frontal cortex oxygenation changes during translation and language switching revealed by noninvasive near-infrared multi-point measurements. Brain Research Bulletin. 59(3):235-243.

RAPPORT, Richard, TAN, C. T. and WHITAKER, Harry (1983): Language function and dysfunction among Chinese- and English-speaking polyglots: Cortical stimulation, Wada testing, and clinical studies. Brain and Language. 18:342-366.

Rinne, Juha, Tommola, Jorma, LAine, Matti, et al. (2000): The translating brain: Cerebral activation patterns during simultaneous interpreting. Neuroscience Letters. 294:85-88.

Schulze, Heinz (1968): Unterschiedliche Ruckbildung einer sensorischen und einer ideokinetischen motorischen Aphasie bei einem Polyglotten. Psychiatrie, Neurologie und Medizinische Psychologie. 20:441-445.

SQuire, Larry (2008): The legacy of patient H.M. for neuroscience. Neuron. 61(1):6-9.

Stengel, Erwin and Zelmanowitz, Joseph (1933): Über polyglotte motorische Aphasie. Zeitschrift für die gesamte Neurologie und Psychiatrie. 1.

Түмосzко, Maria (2012): The neuroscience of translation. Target. 24(1):83-102.

Ullman, Michael (2001): The neural basis of lexicon and grammar in first and second language: The declarative/procedural model. Bilingualism: Language and Cognition. 4(1):105-122.

VeyraC, Guillaume-Julien (1931): Étude de l'aphasie chez les sujets polyglottes. Paris: L. Arnette.

WeEkes, Brendan and Raman, Ilhan (2008): Bilingual deep dysphasia. Cognitive Neuropsychology. 25(3):411-436.

Weisenberg, Theodore and McBride, Katherine (1935): Aphasia: A Clinical and Psychological Study. New York: Hafner. 
APPENDIX

TABLe 1

\section{Summary of hypotheses and empirical predictions}

\begin{tabular}{|c|c|c|}
\hline & HYPOTHESIS & $\begin{array}{l}\text { PREDICTION (SUBSEQUENT TO BRAIN } \\
\text { DAMAGE) }\end{array}$ \\
\hline 1 & $\begin{array}{l}\text { Lexical translation routes are independent } \\
\text { from those supporting monolingual } \\
\text { production. }\end{array}$ & $\begin{array}{l}\text { Either spontaneous monolingual production } \\
\text { or translation skills can be selectively } \\
\text { impaired. }\end{array}$ \\
\hline 2 & $\begin{array}{l}\text { The routes supporting BT and FT are } \\
\text { functionally independent from each other. }\end{array}$ & Either BT or FT can be selectively impaired. \\
\hline 3 & $\begin{array}{l}\text { There is an independent route supporting } \\
\text { form-based translation. }\end{array}$ & $\begin{array}{l}\text { Translation is possible although the } \\
\text { neurological insult impedes conceptual } \\
\text { activations. }\end{array}$ \\
\hline 4 & $\begin{array}{l}\text { Word translation mainly engages posterior } \\
\text { regions implicated in declarative memory. }\end{array}$ & $\begin{array}{l}\text { Word translation impairments should be } \\
\text { greater after posterior than frontobasal } \\
\text { lesions. }\end{array}$ \\
\hline 5 & $\begin{array}{l}\text { Sentence translation mainly engages } \\
\text { frontobasal regions implicated in procedural } \\
\text { memory. }\end{array}$ & $\begin{array}{l}\text { Frontobasal patients should be more } \\
\text { severely impaired in sentence than in word } \\
\text { translation. }\end{array}$ \\
\hline 6 & Translation routes are left-lateralized. & $\begin{array}{l}\text { Translation neuropathologies should occur } \\
\text { exclusively as a result of LH damage. }\end{array}$ \\
\hline
\end{tabular}

\section{TABLE 2}

Symbol and abbreviation key for Tables 3-6

\begin{tabular}{|l|l|}
\hline \multirow{3}{*}{ Symbols } & $\begin{array}{l}\text { *: presumably } \\
\text { ?: information not provided } \\
\text { V: from very good to acceptably good } \\
\text {---: considerably impaired } \\
\text { X: severely impaired } \\
\text { aa: alternating antagonism }\end{array}$ \\
\hline Sex & M: male; F: female \\
\hline Handedness & R: right-handed \\
\hline \multirow{2}{*}{ Languages } & $\begin{array}{l}\text { Ger: German; Eng: English; Fr: French; Cz: Czech; Sp: Spanish; It: Italian; } \\
\text { Rus: Russian; Bul: Bulgarian; Fl: Flemish; Heb: Hebrew; Gal: Galician; } \\
\text { Nep: Nepalese; Far: Farsi; Ven: Venetian; Fri: Friulian; Tur: Turkish; Ar: Arabic }\end{array}$ \\
\hline \multirow{5}{*}{ Etiology } & $\begin{array}{l}\text { Str: stroke; TCH: traumatic cerebral hemorrhage; CT: cranial trauma; } \\
\text { Abs: abscess; Hem: hematoma; Alz: Alzheimer's disease; IC: cerebral infarction; } \\
\text { CIL: chronic inflammatory lesion; LwSO: lesion with sharp object; } \\
\text { Inf: infarction; II: ischemic infarction; CH: cerebral hemorrhage; CC: cerebral } \\
\text { contusion; VM: venous malformation }\end{array}$ \\
\hline \multirow{2}{*}{ Lesion site } & $\begin{array}{l}\text { LH: left hemisphere; RH: right hemisphere; bil: bilateral; FL: frontal lobe; } \\
\text { PL: parietal lobe; TL: temporal lobe; STG: superior temporal gyrus; } \\
\text { PTR: parieto-temporal region; BG: basal ganglia; PPCR: posterior part of the } \\
\text { corona radiata; FTR: fronto-temporal region; NPI: neocortical portions of the } \\
\text { ínsula; POR: parieto-occipital region }\end{array}$ \\
\hline
\end{tabular}


TABLE 3

Compulsive translation: Summary of evidence and additional patient data

\begin{tabular}{|c|c|c|c|c|c|c|c|c|c|}
\hline 嵌 & 罢 & 肴 & 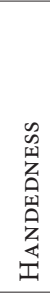 & 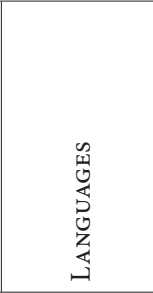 & 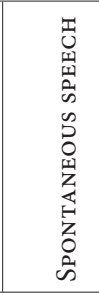 & 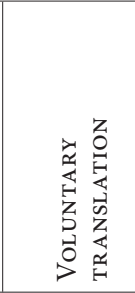 & 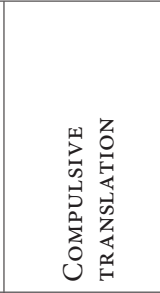 & 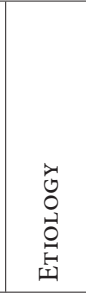 & 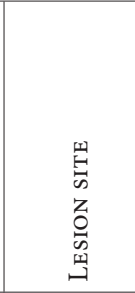 \\
\hline D.O. & 62 & $\mathrm{M}$ & $\mathrm{R}^{*}$ & $\begin{array}{l}\text { L1: Ger } \\
\text { L2: Eng } \\
\text { L3: Fr }\end{array}$ & $\begin{array}{l}\text { L1: X } \\
\text { L2:X } \\
\text { L3:X }\end{array}$ & $?$ & $\begin{array}{l}\text { L2 and/or } \\
\text { L3 } \\
\text { into L1 }\end{array}$ & Str & $\begin{array}{l}\text { LH: STG, } \\
\text { PL }\end{array}$ \\
\hline Ch. & 65 & $\mathrm{~F}$ & $\mathrm{R}^{*}$ & $\begin{array}{l}\text { L1: Eng } \\
\text { L2: Fr }\end{array}$ & $\begin{array}{l}\text { L1: X } \\
\text { L2: X }\end{array}$ & $\begin{array}{l}\text { L1-L2: } X^{*} \\
\text { L2-L1: } X^{*}\end{array}$ & L1 into L2 & Str & $\mathrm{LH}^{*}$ \\
\hline $\begin{array}{l}\text { Case in } \\
\text { Stengel and } \\
\text { Zelmanowitz } \\
(1933)\end{array}$ & 57 & $\mathrm{M}$ & $\mathrm{R}^{\star}$ & $\begin{array}{l}\text { L1: } \mathrm{Cz} \\
\text { L2: Ger }\end{array}$ & $\begin{array}{l}\text { L1: } X^{*} \\
\text { L2: } X^{*}\end{array}$ & $?$ & $\begin{array}{l}\text { L1 into L2 } \\
\text { L2 into L1 }\end{array}$ & $\mathrm{TCH}$ & $\begin{array}{l}\text { LH: } \\
\text { FL }\end{array}$ \\
\hline $\begin{array}{l}\text { Case in } \\
\text { Weisenberg } \\
\text { and McBride } \\
(1935)\end{array}$ & 49 & $\mathrm{M}$ & $\mathrm{R}$ & $\begin{array}{l}\text { L1: Eng } \\
\text { L2: Sp } \\
\text { L3: Fr } \\
4 \text { more }\end{array}$ & ? & $\begin{array}{l}\text { L1-L2: --- } \\
\text { L1-L3: --- }\end{array}$ & $\begin{array}{l}\text { L1 into L2 } \\
\text { \& L3 }\end{array}$ & $?$ & $\begin{array}{l}\mathrm{LH}^{*}: \\
\mathrm{FL}^{*}\end{array}$ \\
\hline \begin{tabular}{|l|} 
Jakobson \\
$(1964)$
\end{tabular} & $?$ & $\mathrm{M}$ & $\mathrm{R}$ & $\begin{array}{l}\text { L1: Rus } \\
\text { L2: Fr, Ger, } \\
\text { others }\end{array}$ & $?$ & $?$ & $\begin{array}{l}\text { L1 into L2, } \\
\text { L3, L4 \& L5 }\end{array}$ & $\mathrm{CC}$ & LH \\
\hline $\begin{array}{l}\text { Case in } \\
\text { Schulze } \\
(1968)\end{array}$ & $?$ & $\mathrm{M}$ & $\mathrm{R}$ & $\begin{array}{l}\text { L1: Bul } \\
\text { L2: Ger } \\
\text { others }\end{array}$ & $\begin{array}{l}\text { L1: --- } \\
\text { L2: --- }\end{array}$ & $?$ & L2 into L1 & Abs & LH: PTR \\
\hline H.B. & 80 & $\mathrm{M}$ & $\mathrm{R}^{*}$ & $\begin{array}{l}\text { L1: Ger } \\
\text { L2: Fr } \\
\text { L3: Eng }\end{array}$ & $\begin{array}{l}\text { L1:? } \\
\text { L2:? } \\
\text { L3:X }\end{array}$ & $\begin{array}{l}\text { erratic in } \\
\text { every } \\
\text { direction }\end{array}$ & L1 into L3 & Hem & $\begin{array}{l}\text { Bil: } \\
\text { TL }\end{array}$ \\
\hline N.T. & 65 & $\mathrm{M}$ & $\mathrm{R}$ & $\begin{array}{l}\text { L1: It } \\
\text { L2: Fr } \\
\text { L3: Eng } \\
\text { L4: Ger }\end{array}$ & $\begin{array}{l}\text { L1: --- } \\
\text { L2: X } \\
\text { L3:X } \\
\text { L4: X }\end{array}$ & $\begin{array}{l}\text { L1-L2: } \sqrt{ } \\
\text { L1-L3:X } \\
\text { L2-L1: X } \\
\text { L3-L1: X }\end{array}$ & $\begin{array}{l}\text { into every } \\
\text { language, } \\
\text { but } \\
\text { specially L2 }\end{array}$ & $\mathrm{Alz}$ & $\begin{array}{l}\text { LH: } \\
\text { TL }\end{array}$ \\
\hline $\begin{array}{l}\text { Case in } \\
\text { Lebrun (1991) }\end{array}$ & $?$ & $\mathrm{M}$ & $\mathrm{R}^{*}$ & $\begin{array}{l}\text { L1: } \mathrm{Fl} \\
\text { L2: } \mathrm{Fr}\end{array}$ & $\begin{array}{l}\text { L1: } \sqrt{ } \\
\text { L2: } \sqrt{ }\end{array}$ & $?$ & $\begin{array}{l}\text { L2 into L1, } \\
\text { written } \\
\text { mode }\end{array}$ & $?$ & $\mathrm{RH}$ \\
\hline R.K. & 68 & $\mathrm{~F}$ & $\mathrm{R}$ & $\begin{array}{l}\text { L1: Rus } \\
\text { L2: Heb }\end{array}$ & $\begin{array}{l}\text { L1: --- } \\
\text { L2: --- }\end{array}$ & $\begin{array}{l}\text { L1-L2: X } \\
\text { L2-L1: X }\end{array}$ & L2 into L1 & Str & $\begin{array}{l}\text { LH: } \\
\text { BG, PPCR }\end{array}$ \\
\hline $\begin{array}{l}\text { Case in } \\
\text { G.-Caballero, } \\
\text { G-Lado et al. } \\
(2007)\end{array}$ & 91 & $\mathrm{~F}$ & $\mathrm{R}$ & $\begin{array}{l}\text { L1: Gal } \\
\text { L2: Sp }\end{array}$ & $\begin{array}{l}\text { L1: X } \\
\text { L2: } \sqrt{ }\end{array}$ & \begin{tabular}{|l} 
L1-L2:? \\
L2-L1: --- \\
(words)
\end{tabular} & L1 into L2 & CI & $\begin{array}{l}\text { RH: BG } \\
\text { (crossed } \\
\text { aphasia) }\end{array}$ \\
\hline
\end{tabular}




\section{TABle 4}

Inability to translate: Summary of evidence and additional patient data

\begin{tabular}{|c|c|c|c|c|c|c|c|c|c|}
\hline ن & 罗 & 离 & 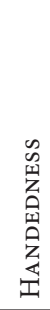 & 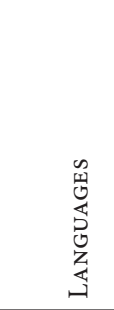 & 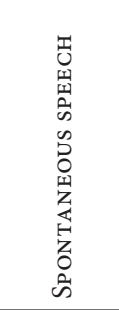 & 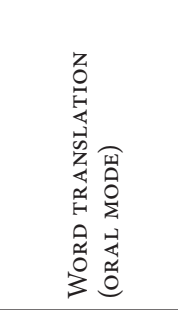 & 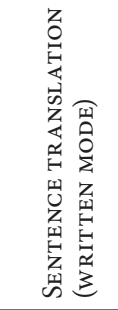 & 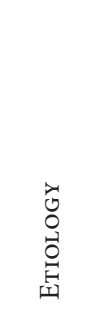 & 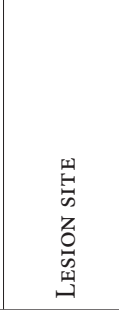 \\
\hline $\begin{array}{l}\text { Case in } \\
\text { Gastaldi (1951) }\end{array}$ & 42 & M & $\mathrm{R}^{*}$ & $\begin{array}{l}\text { L1: Ger } \\
\text { L2: It }\end{array}$ & $\begin{array}{l}\text { L1: --- } \\
\text { L2: --- }\end{array}$ & $\begin{array}{l}\text { L1-L2: X } \\
\text { L2-L1: X }\end{array}$ & $\begin{array}{l}\text { L1-L2:? } \\
\text { L2-L1:? }\end{array}$ & CIL & LH \\
\hline H.B. & 80 & $\mathrm{M}$ & $\mathrm{R}^{*}$ & $\begin{array}{l}\text { L1: Ger } \\
\text { L2: Fr } \\
\text { L3: Eng }\end{array}$ & $\begin{array}{l}\text { L1:? } \\
\text { L2:? } \\
\text { L3: X }\end{array}$ & $\begin{array}{l}\text { L1-L2: } X^{*} \\
\text { L1-L3: } X^{\star} \\
\text { L3-L2: } X^{*}\end{array}$ & $?$ & Hem & Bil: TL \\
\hline B. & 15 & $\mathrm{M}$ & $\mathrm{R}$ & $\begin{array}{l}\text { L1: Nep } \\
\text { L2: Eng }\end{array}$ & $\begin{array}{l}\text { L1: X } \\
\text { L2: } \sqrt{ } \\
\text { (out- } \\
\text { loud } \\
\text { reading) }\end{array}$ & $\begin{array}{l}\text { L1-L2: } \sqrt{ } \\
\text { L2-L1: X } \\
\text { (sight } \\
\text { translation) }\end{array}$ & $\begin{array}{l}\text { L1-L2:? } \\
\text { L2-L1:? }\end{array}$ & LwSO & $\begin{array}{l}\text { LH: PL, } \\
\text { TL }\end{array}$ \\
\hline A.S. & 49 & $M$ & $\mathrm{R}$ & $\begin{array}{l}\text { L1: Far } \\
\text { L2: Eng } \\
\text { L3: Ger }\end{array}$ & $\begin{array}{l}\text { L1: aa } \\
\text { L2: X } \\
\text { L3: aa }\end{array}$ & $\begin{array}{l}\text { L1-L2: X } \\
\text { L2-L1: X } \\
\text { L1-L3: X } \\
\text { L3-L1: --- }\end{array}$ & $\begin{array}{l}\text { L1-L2: X } \\
\text { L2-L1: X } \\
\text { L1-L3:? } \\
\text { L3-L1:? }\end{array}$ & CC & LH: FTR \\
\hline E.M. & 70 & $\mathrm{~F}$ & $\mathrm{R}$ & $\begin{array}{l}\text { L1: Ven } \\
\text { L2: It }\end{array}$ & $\begin{array}{l}\text { L1: X } \\
\text { L2:--- }\end{array}$ & $\begin{array}{l}\text { L1-L2: } \\
\text { L2-L1: --- }\end{array}$ & $\begin{array}{l}\text { L1-L2: } \\
\text { L2-L1: X }\end{array}$ & Inf & LH: BG \\
\hline C.B. & 71 & $\mathrm{~F}$ & $\mathrm{R}$ & $\begin{array}{l}\text { L1: Fri } \\
\text { L2: It } \\
\text { L3: Eng }\end{array}$ & $\begin{array}{l}\text { L1: X } \\
\text { L2: X } \\
\text { L3:X }\end{array}$ & $\begin{array}{l}\text { L1-L2: } \sqrt{ } \\
\text { L2-L1: --- } \\
\text { L1-L3: --- } \\
\text { L3-L1: X } \\
\text { L2-L3: X } \\
\text { L3-L2: X }\end{array}$ & $\begin{array}{l}\text { L1-L2: X } \\
\text { L2-L1: X } \\
\text { L1-L3:X } \\
\text { L3-L1: X } \\
\text { L2-L3: X } \\
\text { L3-L2: X }\end{array}$ & II & LH: BG \\
\hline El.M. & 56 & $\mathrm{M}$ & $\mathrm{R}$ & $\begin{array}{l}\text { L1: Fri } \\
\text { L2: It }\end{array}$ & $\begin{array}{l}\text { L1: X } \\
\text { L2: X }\end{array}$ & $\begin{array}{l}\text { L1-L2: } \sqrt{ } \\
\text { L2-L1: }\end{array}$ & $\begin{array}{l}\text { L1-L2: X } \\
\text { L2-L1: X }\end{array}$ & $\mathrm{CH}$ & LH: BG \\
\hline O.R. & 63 & $\mathrm{M}$ & $\mathrm{R}^{*}$ & $\begin{array}{l}\text { L1: Fri } \\
\text { L2: It }\end{array}$ & $\begin{array}{l}\text { L1: } \sqrt{ } \\
\text { L2: } \sqrt{ }\end{array}$ & $\begin{array}{l}\text { L1-L2: } \\
\text { L2-L1: X }\end{array}$ & $\begin{array}{l}\text { L1-L2: X } \\
\text { L2-L1: X }\end{array}$ & II & $\begin{array}{l}\text { LH: BG, } \\
\text { NPI }\end{array}$ \\
\hline R.K. & 68 & $\mathrm{~F}$ & $\mathrm{R}$ & $\begin{array}{l}\text { L1: Rus } \\
\text { L2: Heb }\end{array}$ & $\begin{array}{l}\text { L1: --- } \\
\text { L2: --- }\end{array}$ & $\begin{array}{l}\text { L1-L2: X } \\
\text { L2-L1: X }\end{array}$ & $?$ & Str & $\begin{array}{l}\text { LH: BG, } \\
\text { PPCR }\end{array}$ \\
\hline B.R.B. & 67 & $M$ & $\mathrm{R}$ & $\begin{array}{l}\text { L1: Tur } \\
\text { L2: Eng }\end{array}$ & $\begin{array}{l}\text { L1: --- } \\
\text { L2: --- }\end{array}$ & $\begin{array}{l}\text { L1-L2:? } \\
\text { L2-L1: } \\
\text { sight trans.: } \sqrt{ } \\
\text { oral trans.: } \mathrm{X}\end{array}$ & $\begin{array}{l}\text { L1-L2:? } \\
\text { L2-L1:? }\end{array}$ & Str & LH: POR \\
\hline
\end{tabular}




\section{TABLE 5}

Paradoxical translation behavior: Summary of evidence and additional patient data

\begin{tabular}{|c|c|c|c|c|c|c|c|c|c|}
\hline 点 & 跑 & 希 & 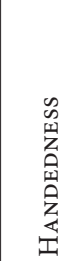 & 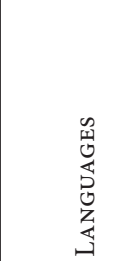 & 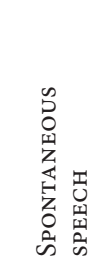 & 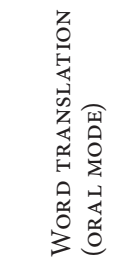 & 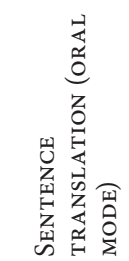 & 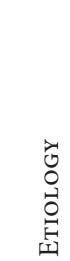 & 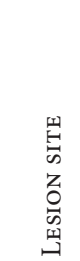 \\
\hline \multirow[t]{2}{*}{ A.D. } & \multirow[t]{2}{*}{48} & \multirow[t]{2}{*}{$\mathrm{F}$} & \multirow[t]{2}{*}{$\mathrm{R}$} & \multirow[t]{2}{*}{$\begin{array}{l}\text { L1: } \mathrm{Fr} \\
\text { L2: Ar }\end{array}$} & $\begin{array}{l}\text { L1: } \sqrt{ } \\
\text { L2: X }\end{array}$ & $\begin{array}{l}\text { L1-L2: } \\
\text { L2-L1: X }\end{array}$ & $\begin{array}{l}\text { L1-L2: } \\
\text { L2-L1: X }\end{array}$ & \multirow[t]{2}{*}{$\mathrm{CC}$} & \multirow[t]{2}{*}{$\begin{array}{l}\text { LH: } \\
\text { RTOP }\end{array}$} \\
\hline & & & & & $\begin{array}{l}\text { L1: X } \\
\text { L2: } \sqrt{ }\end{array}$ & $\begin{array}{l}\text { L1-L2: X } \\
\text { L2-L1: }\end{array}$ & $\begin{array}{l}\text { L1-L2: X } \\
\text { L2-L1: }\end{array}$ & & \\
\hline \multirow[t]{2}{*}{ C.P. } & \multirow[t]{2}{*}{23} & \multirow[t]{2}{*}{$M$} & \multirow[t]{2}{*}{$\mathrm{R}$} & \multirow[t]{2}{*}{$\begin{array}{l}\text { L1: Fr } \\
\text { L2: Eng }\end{array}$} & $\begin{array}{l}\text { L1: } \sqrt{ } \\
\text { L2: X }\end{array}$ & $\begin{array}{l}\text { L1-L2:? } \\
\text { L2-L1:? }\end{array}$ & $\begin{array}{l}\text { L1-L2: } \\
\text { L2-L1: X }\end{array}$ & \multirow[t]{2}{*}{ VM } & \multirow[t]{2}{*}{$\begin{array}{l}\text { LH: } \\
\text { RTP }\end{array}$} \\
\hline & & & & & $\begin{array}{l}\text { L1: X } \\
\text { L2: } \sqrt{ }\end{array}$ & $\begin{array}{l}\text { L1-L2:? } \\
\text { L2-L1:? }\end{array}$ & $\begin{array}{l}\text { L1-L2:? } \\
\text { L2-L1:? }\end{array}$ & & \\
\hline N.T. & 65 & $M$ & R & $\begin{array}{l}\text { L1: It } \\
\text { L2: Fr } \\
\text { and others }\end{array}$ & $\begin{array}{l}\text { L1: --- } \\
\text { L2: X }\end{array}$ & $\begin{array}{l}\text { L1-L2:? } \\
\text { L2-L1:? }\end{array}$ & $\begin{array}{l}\text { L1-L2: } \\
\text { L2-L1: X }\end{array}$ & $\mathrm{Alz}$ & $\begin{array}{l}\text { LH: } \\
\text { TL }\end{array}$ \\
\hline
\end{tabular}

TABLE 6

Translation without comprehension: Summary of evidence and additional patient data

\begin{tabular}{|c|c|c|c|c|c|c|c|c|c|}
\hline 峁 & 罗 & 离 & 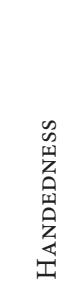 & 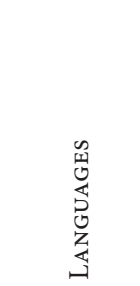 & 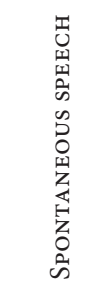 & 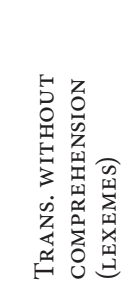 & 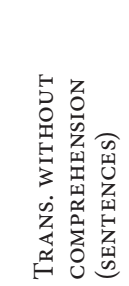 & 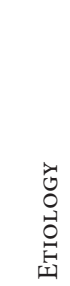 & 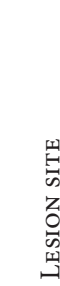 \\
\hline Ch. & 65 & F & $\mathrm{R}^{*}$ & $\begin{array}{l}\text { L1: Eng } \\
\text { L2: Fr }\end{array}$ & $\begin{array}{l}\text { L1:X } \\
\text { L2:X }\end{array}$ & L1 into L2 & $?$ & Str & $\mathrm{LH}^{*}$ \\
\hline \multirow[t]{2}{*}{ C.P. } & \multirow[t]{2}{*}{23} & \multirow[t]{2}{*}{$M$} & \multirow[t]{2}{*}{$\mathrm{R}$} & \multirow[t]{2}{*}{$\begin{array}{l}\text { L1: Fr } \\
\text { L2: Eng }\end{array}$} & $\begin{array}{l}\text { L1: } \sqrt{ } \\
\text { L2: X }\end{array}$ & L1 into L2 & $?$ & \multirow[t]{2}{*}{ VM } & \multirow[t]{2}{*}{$\begin{array}{l}\text { LH: } \\
\text { RTP }\end{array}$} \\
\hline & & & & & $\begin{array}{l}\text { L1: X } \\
\text { L2: } \sqrt{ }\end{array}$ & $?$ & $?$ & & \\
\hline N.T. & 65 & M & $\mathrm{R}$ & $\begin{array}{l}\text { L1: It } \\
\text { L2: Fr } \\
\text { and others }\end{array}$ & $\begin{array}{l}\text { L1: --- } \\
\text { L2: X }\end{array}$ & L1 into L2 & $?$ & $\mathrm{Alz}$ & $\begin{array}{l}\text { LH: } \\
\text { TL }\end{array}$ \\
\hline
\end{tabular}

